\title{
СЕКЦІЯ «ІНФОРМАТИКА»
}

\section{УДК 519.6:004.8}

DOI 10.31651/2076-5886-2020-1-61-68

PACS 02.60.-x, 02.60.Pn, 02.70.Wz
ПШЕНИШНИЙ Олександр Вадимович, студент спеціальності «Інформаційні системи та технології» Черкаського національного університету імені Богдана Хмельницького e-mail: X3morph@gmail.com

\section{КРАСНОШЛИК Наталія} Олександрівна, кандидат технічних наук, доцент, доцент кафедри прикладної математики та інформатики Черкаського національного університету імені Богдана

Хмельницького e-mail:wlik007@ukr.net ORCID 0000-0003-4661-6997

\section{ДОСЛІДЖЕННЯ ЕФЕКТИВНОСТІ ПОПУЛЯЦЙННИХ АЛГОРИТМІВ ДЛЯ РОЗВ'ЯЗУВАННЯ ЗАДАЧ ГЛОБАЛЬНОЇ ОПТИМІЗАЦІї}

У роботі розглянуто алгоритми кажанів, світлячків та зозулі для розв'язування задачі глобальної оптимізачії. Дані метаевристичні алгоритм відноситься до популяційних алгоритмів, які інтенсивно розвиваються в останні роки. Метою роботи є реалізація та дослідження ефективності їх роботи при розв 'язуванні оптимізаційних задач. Досліджено залежність точності й ефективності роботи розглянутих популяційних алгоритмів від параметрів, які задаються, та знайдено їх оптимальні значення. Проведено обчислювальні експерименти з порівняння точності знаходженні глобального мінімуму унімодальних і мультимодальних тестових функиій.

Встановлено, щзо розглянуті популяціийні алгоритми $\epsilon$ ефективною альтернативою класичним методам розв'язування оптимізаційних задач, оскільки не накладають жодних обмежень на вигляд иільової функиії.

Ключові слова: популяційний алгоритм, ройовий інтелект, глобальна оптимізація, алгоритм кажанів, алгоритм світлячків, алгоритм зозулі.

\section{Постановка проблеми}

Розв'язування багатьох актуальних технічних, економічних, фізичних, біомедицинських та інших задач зводиться до задач глобальної оптимізації. Чисельні методи оптимізації можна умовно розділити на детерминистические та стохастичні. Детерміністичні методи, як правило, передбачають знаходження градієнта цільової функції і залежать від вибору початкових значень. Широкого розповсюдження набувають стохастичні методи, які почали інтенсивно розвиватися в 1980-х рр. Відповідні методи в літературі називають метаеврестичними, популяційними, багатоагентними і алгоритмами ройового інтелекту (Swarm intelligence) [1].

Метаеврестичні алгоритми передбачають одночасну обробку декількох можливих варіантів розв'язку оптимізаційної задачі. Ще однією особливістю подібних алгоритмів 
$€$ ï біонічна природа. Популяційні алгоритми описують динаміку поведінки груп різних соціальних тварин, птахів, комах та інших агентів деякої біологічної системи, які локально взаємодіють між собою і 3 навколишнім середовищем. Колективна поведінка групи агентів дозволяє їм вирішувати різні складні практичні задачі у природі, що свідчить про ефективність алгоритмів ройового інтелекту, які моделюють ïx поведінку [2]. Тому досить актуальною $є$ задача розробки та дослідження популяційних алгоритмів для розв'язування оптимізаційних задач.

Серед різноманіття популяційних алгоритмів можна виділити наступні [3]:

- алгоритми, інспіровані живою природою (nature-inspired algorithms);

- алгоритми, інспіровані неживою природою;

- алгоритми, інспіровані людським суспільством та інші.

До найбільш відомих алгоритмам, натхненних живою природою, відносяться: мурашиний алгоритм (Ant Colony Optimization), метод рою частинок (Particle Swarm Optimization), бактеріальна оптимізація (Bacterial Optimisation), алгоритм бджолиного рою (Bees Algorithm), алгоритм світлячків (Firefly Algorithm), пошук косяком риб (Fish School Searh), алгоритм зозулі (Cuckoo Search), алгоритм кажанів (Bat Algorithm) та ін.

Алгоритми, інспіровані неживою природою, імітують процеси, що відбуваються у фізиці, хімії і т.п., зокрема це: стохастичний дифузійний пошук (Stochastic Diffusion Search), диференціальна еволюція (Differential Evolution), електромагнітний алгоритм (ElectroMagnetism-like Algorithm), гармонійний пошук (Harmony Search), алгоритм гравітаційного пошуку (Gravitational Search) та ін.

До алгоритмів, інспіровані людським суспільством, належать: алгоритм еволюції розуму (Mind Evolutionary Computation), культурний алгоритм (Cultural Algorithm) та iн.

Об'єктом даного дослідження $є$ процес розв'язування задач глобальної оптимізації за допомогою популяційних алгоритмів. Предметом дослідження виступають популяційні алгоритм світлячків, кажанів та зозулі.

Метою даної статті є реалізація та дослідження ефективності популяційних алгоритм кажанів, світлячків та зозулі для розв'язування задач глобальної оптимізації.

\section{Методи розв'язання}

Розглянемо наступну задачу. Задано цільову функцію $f(x)$, яка визначена на множині допустимих розв'язків $X \subseteq R^{m}$.

Потрібно знайти глобальний умовний мінімум функції $f(x)$ на множині $X$ :

$$
f\left(x^{*}\right)=\min _{x \in X \subseteq R^{m}} f(x),
$$

де $x=\left(x_{1}, x_{2}, \ldots, x_{m}\right)^{T}, X=\left\{x \mid x_{i} \in\left[x_{\min }, x_{\max }\right], i \in \overline{1, m}\right\}$.

Задача пошуку максимуму функції $f(x)$ зводиться до задачі пошуку мінімуму:

$f\left(x^{*}\right)=\max _{x \in X \subseteq R^{m}} f(x)=-\min _{x \in X \subseteq R^{m}}(-f(x))$.

Алгоритм світлячків (Firefly algorithm) був запропонований Xin-She Yang y 2008 р. Даний алгоритм використовує наступну модель поведінки світлячків [4]:

- світлячки породжують світло 3 інтенсивністю $I$, яка обернено пропорційна квадрату відстані. Ця здатність свідчить про те, що світлячок $є$ видимим на обмежений відстані. Світло допомагає йому притягувати їжу та партнерів; 
- привабливість світлячка пропорційна яскравості, тому у випадковій парі світлячків менш яскравий буде прагнути до більш яскравого;

- яскравість зменшується зі збільшенням відстані. Якщо не має більш яскравого світлячка, то він буде рухатися випадковим чином. Яскравість ототожнюється 3 величиною цільової функції.

Привабливість визначається двома факторами: величиною цільової функції i відстанню до світлячка. Яскравість залежно від відстані до джерела визначається відповідно до закону:

$$
I=\frac{I_{0}}{1+\gamma r^{2}}
$$

де $I_{0}$ - інтенсивність джерела, $r$ - відстань до нього, $\gamma$ - заданий коефіцієнт (визначає поглинання світла).

В якості функції I можуть бути використані і інші монотонно спадаючі функції, наприклад:

$$
I=I_{0} e^{-\gamma r^{2}} .
$$

Тоді привабливість світлячка $i$-го для $j$-го визначається формулою:

$$
\beta_{i j}=\beta_{0} e^{-\gamma r_{i j}^{2}} \text {, }
$$

де $\beta_{i j}$ - взаємна привабливість світлячків, $r_{i j}=\sqrt{\sum_{k=1}^{m}\left(r_{k}^{i}-r_{k}^{j}\right)^{2}}-$ відстань між ними.

Алгоритм світлячків для розв’язання задачі глобальної мінімізації полягає у наступному:

1: Ініціалізація початкової популяції (задати початкове положення $x_{i}$ кожного $i$-го світлячка, $i=\overline{1, N})$ та параметрів алгоритму $(\alpha$ i $\gamma)$.

2: while $(t \leq t$ Max $)$

3: $\quad$ for $i=\overline{1, N}$

4: $\quad$ for $j=\overline{1, N}$

5: $\quad$ if $f\left(x_{j}\right)<f\left(x_{i}\right)$

6: $\quad$ Переміщення $j$-го світлячка у напрямку $i$-го за формулою:

$$
x^{j}=x^{i}+\beta_{0} e^{-\gamma r_{i j}^{2}} \cdot\left(x^{i}-x^{j}\right)+\alpha \cdot \varepsilon^{j} .
$$

\section{7: $\quad$ end if}

8: $\quad$ Оцінюємо нові рішення та інтенсивність оновлення світла.

9: $\quad$ end for

10: end for

11: Знаходимо краще поточне положення світлячка.

12: Збільшити лічильник кількості ітерацій $t \leftarrow t+1$.

13: end while

Алгоритм кажанів (Bat Algorithm) був запропонований Xin-She Yang y 2010 p. i $\epsilon$ потенційно більш потужним, ніж алгоритм рою часток або генетичний алгоритм. Основними складовими алгоритму є: особливості переміщення кажанів у просторі та характеристики звукових сигналів, які вони генерують.

Робота алгоритму грунтується на наступній моделі поведінки кажанів [5-7]:

- усі кажани використовують ехолокацію, щоб визначати відстань, а також розрізняти їжу/здобич і перешкоди. 
- поточне положення кожного кажана позначимо $x_{i}, 3$ нього він переміщується випадковим чином зі швидкістю $v_{i}$. У процесі руху кажани генерують звукові сигнали, що мають частоту $\omega_{i}$ і гучність $A_{i}$. При цьому вони можуть змінювати як частоту, так $\mathrm{i}$ інтенсивність звукових імпульсів $r_{i} \in[0,1]$, залежно від близькості до цілі.

- гучність звукового сигналу змінюється від більшого початкового значення $A_{0}$ до меншого заданого $A_{\min }$.

Алгоритм кажанів для розв'язання задачі глобальної мінімізації полягає у наступному:

1: Ініціалізація початкової популяції (задати початкове положення $x_{i}$ кожного $i$-го кажана, $i=\overline{1, N})$ та параметрів алгоритму $\left(\omega_{i}-\right.$ частота, $r_{i}-$ інтенсивність, $A_{i}-$ гучність звукових імпульсів кажанів).

2: while $(t \leq t$ Max $)$

3: $\quad$ for $i=\overline{1, N}$

4: $\quad$ Переміщення кожного $i$-го кажана за формулами:

$$
\begin{gathered}
\omega_{i}=\omega_{\min }+\left(\omega_{\max }-\omega_{\min }\right) \cdot \beta, \\
v_{i}^{(t+1)}=v_{i}^{(t)}+\left(x_{i}^{(t)}-\bar{x}\right) \cdot \omega_{i} \\
x_{i}^{(t+1)}=x_{i}^{(t)}+v_{i}^{(t+1)},
\end{gathered}
$$

де $\omega_{i} \in\left[\omega_{\min }, \omega_{\max }\right]-$ частота; $\bar{x}-$ положення кажана, в якому знайдено кращий глобальний розв’язок; $\bar{x}_{i}$ - положення кажана, в якому знайдено кращий розв'язок даним кажаном окремо; $\beta$ - випадкове число з інтервалу $[0,1]$;

5: $\quad$ if $\left(\right.$ rand $\left.>r_{i}\right)$

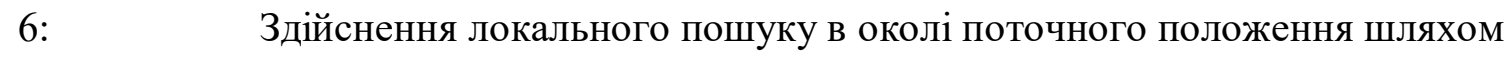
випадкового блукання за формулою:

$$
x_{i}^{(\text {new })}=x_{i}^{(\text {old })}+\varepsilon \cdot \bar{A}(t),
$$

де $\bar{A}(t)$ - середнє значення гучності звукових сигналів всіх кажанів; $\varepsilon-$ випадкове число з інтервалу $[-1,1]$.

7: $\quad$ end if

8: $\quad$ if $\left(\right.$ rand $<A_{i}$ and $\left.f\left(x_{i}^{(\text {new })}\right)<f(\bar{x})\right)$

9 : $\quad$ Прийняти нове положення кажана.

10: $\quad$ Зменшити $A_{i}$ і збільшити $r_{i}$ за формулами:

$$
A_{i}^{(\mathrm{t}+1)}=\alpha \cdot A_{i}^{(\mathrm{t})}, r_{i}^{(\mathrm{t}+1)}=r_{i}^{(0)} \cdot\left(1-e^{-\gamma t}\right),
$$

де $\alpha, \gamma$-задані коефіцієнти.

11: $\quad$ end if

12: Оновити $\bar{x}$.

13: end for

14: Збільшити лічильник кількості ітерацій $t \leftarrow t+1$.

15: end while 
Алгоритм зозулі (Cuckoo search) був запропонований Xin-She Yang та Suash Deb у 2009 р. Натхненням для його створення послужив гніздовий паразитизм деяких видів зозуль, що підкладають свої яйця до гнізд інших птахів.

Робота алгоритму грунтується на наступній моделі поведінки даних птахів [8]:

- кожна зозуля відкладає одне яйце за один раз, і підкидає його в гніздо, яке вибирає випадково;

- найкращі яйця з найкращою оцінкою (потрібними розв'язками) переходять на наступне покоління;

- число доступних гнізд фіксовано, а яйце зозулі може бути знайдене господарем 3 ймовірністю $p \in[0 ; 1]$. Виявленні розв'язки виключаються із подальшого розв'язування.

Алгоритм зозулі для розв'язання задачі глобальної мінімізації полягає у наступному:

1: Ініціалізація початкової популяції (задати початкові положення гнізд $x_{i}, i=\overline{1, N}$ ) та параметрів алгоритму ( $\lambda$ - параметр розподілу Леві, $p$ - частина гнізд, які видаляються, $\alpha$ - параметр зміни кроку).

2: while $(t \leq t$ Max $)$

3: $\quad$ for $i=\overline{1, N}$

4: $\quad$ Переміщення зозулі випадковим чином, відповідно до польотів Леві

$$
x_{i}^{(t+1)}=x_{i}^{(t)}+\frac{\alpha}{t+1} \cdot \operatorname{Levy}(\lambda),
$$

де $\operatorname{Levy}(\lambda)$ - випадкова величина, що генерується розподілом Леві; $\alpha$ величина кроку.

5: $\quad$ Вибрати випадковим чином гніздо $x_{j}$.

6: $\quad$ if $f\left(x_{i}\right)>f\left(x_{j}\right)$

7: $\quad$ Замінити гніздо з номером $j$ на нове.

8: $\quad$ end if

9: $\quad$ Частину гнізд, виявлених із ймовірністю $p$, видалити із популяції.

10: Згенерувати таку ж кількість нових гнізд.

11: end for

12: Знаходимо краще поточне гніздо.

13: Збільшити лічильник кількості ітерацій $t \leftarrow t+1$.

14: end while

\section{Результати дослідження}

Для проведення обчислювальних експериментів обрали наступні тестові функції:

1) функція де Джонга: $f_{1}(x)=\sum_{i=1}^{m} x_{i}^{2}, \quad-10 \leq x_{i} \leq 10$. Глобальний мінімум функції $f_{1}\left(x^{*}\right)=0$ при $x^{*}=(0,0, \ldots, 0)$.

2) функція Розенброка: $f_{2}(x)=\sum_{i=1}^{m-1}\left(\left(x_{i}-1\right)^{2}+100\left(x_{i+1}-x_{i}^{2}\right)^{2}\right), \quad-5 \leq x_{i} \leq 5$. Глобальний мінімум функції $f_{2}\left(x^{*}\right)=0$ при $x^{*}=(1,1, \ldots, 1)$. 
3) функція Растригіна: $f_{3}(x)=\sum_{i=1}^{m}\left(x_{i}^{2}-10 \cos \left(2 \pi x_{i}\right)\right)+10 m, \quad-5 \leq x_{i} \leq 5 . \quad$ Глобальний мінімум функції $f_{3}\left(x^{*}\right)=0$ при $x^{*}=(0,0, \ldots, 0)$.

Популяційні алгоритми світлячків, кажанів та зозулі реалізовані у середовищі MATLAB R2012b. Для кожного алгоритму експериментально встановлені значення констант і параметрів, при яких знайдено порівняно найкращі розв'язки.

Для алгоритму світлячків обрано наступні значення: $\alpha=0.15, \gamma=1, \beta_{0}=0.1$. Для алгоритму кажанів обрано параметри і початкові значення: $\alpha=0.9, \gamma=0.9 A_{i}^{(0)}=0.35$, $r_{i}^{(0)}=0.4$. А у алгоритмі зозулі обрали: $p=0.25, \lambda=1.5, \alpha=1$. У всіх алгоритмах покладали $t$ Max $=1000, N=20$.

Алгоритми кажанів, світлячків та зозулі містять ряд варійованих параметрів, від значення яких, може сильно залежить їх ефективність. Крім того, вплив даних параметрів сильно залежить від виду цільової функції. Тому оптимальні значення вхідних параметрів для розглянутих алгоритмів повинні вибиратися в кожному конкретному випадку індивідуально.

При порівнянні результатів розв'язування задачі (1), кожен алгоритм застосовувався для кожної функції 50 разів. Отримані результати для набору тестових функцій наведено в табл. 1.

Таблиця 1

Результати обчислювальних експериментів для тестових функцій

\begin{tabular}{|c|c|c|c|c|}
\hline $\begin{array}{l}\text { Тестова } \\
\text { функція }\end{array}$ & $\begin{array}{c}\text { Розмірність } \\
\text { простору, } \\
m\end{array}$ & Алгоритм & $\begin{array}{c}\text { Краще отримане } \\
\text { значення цільової } \\
\text { функції }\end{array}$ & $\begin{array}{c}\text { Середнє серед } \\
\text { отриманих значень } \\
\text { цільової функції }\end{array}$ \\
\hline \multirow{6}{*}{$f_{1}(x)$} & \multirow{3}{*}{5} & світлячків & $1.5678 \mathrm{e}-03$ & $5.6784 \mathrm{e}-01$ \\
\hline & & кажанів & $7.5366 \mathrm{e}-03$ & $3.4367 \mathrm{e}-01$ \\
\hline & & зозулі & $8.8369 \mathrm{e}-03$ & $9.4356 \mathrm{e}-01$ \\
\hline & \multirow{3}{*}{10} & світлячків & $1.0420 \mathrm{e}-01$ & $5.1940 \mathrm{e}-00$ \\
\hline & & кажанів & $2.5723 \mathrm{e}-01$ & $5.6863 \mathrm{e}+00$ \\
\hline & & зозулі & $1.6783 \mathrm{e}-02$ & $6.4344 \mathrm{e}-01$ \\
\hline \multirow{6}{*}{$f_{2}(x)$} & \multirow{3}{*}{5} & світлячків & $7.5366 \mathrm{e}+00$ & $5.5676 \mathrm{e}+01$ \\
\hline & & кажанів & $4.8717 \mathrm{e}+00$ & $7.8534 \mathrm{e}+01$ \\
\hline & & зозулі & $6.8576 \mathrm{e}-01$ & $0.8943 \mathrm{e}+01$ \\
\hline & \multirow{3}{*}{10} & світлячків & $5.7401 \mathrm{e}+01$ & $8.8465 \mathrm{e}+02$ \\
\hline & & кажанів & $4.8663 \mathrm{e}+01$ & $6.8372 \mathrm{e}+02$ \\
\hline & & зозулі & $3.8672 \mathrm{e}+01$ & $6.9383 \mathrm{e}+02$ \\
\hline \multirow{6}{*}{$f_{3}(x)$} & \multirow{3}{*}{5} & світлячків & $8.6573 e+00$ & $4.7822 \mathrm{e}+01$ \\
\hline & & кажанів & $9.2335 \mathrm{e}+00$ & $7.1244 \mathrm{e}+01$ \\
\hline & & зозулі & $1.9023 \mathrm{e}-01$ & $6.3476 \mathrm{e}+00$ \\
\hline & \multirow{3}{*}{10} & світлячків & $3.6533 \mathrm{e}+01$ & $9.7634 \mathrm{e}+01$ \\
\hline & & кажанів & $4.2676 \mathrm{e}+01$ & $9.7346 \mathrm{e}+01$ \\
\hline & & зозулі & $9.9703 \mathrm{e}+00$ & $7.8352 \mathrm{e}+01$ \\
\hline
\end{tabular}

Результати обчислювальних експериментів показали, що в окремих випадках алгоритм зозулі $є$ більш ефективним у порівнянні 3 іншими алгоритмами для розв’язування задачі глобальної оптимізації.

В цілому, розглянуті популяційні алгоритми $\epsilon$ ефективною альтернативою класичним методам розв'язування оптимізаційних задач, оскільки є нескладними для 
програмної реалізації, невибагливими до виду цільової функції та дозволяють знайти розв'язок з порівняно високою точністю.

\section{Висновки}

У роботі розглянуто задачу знаходження глобального мінімуму цільової функції за допомогою алгоритмів, інспірованих поведінкою кажанів, світлячків та зозулі, які відносяться до популяційних алгоритмів.

Здійснено програмну реалізацію даних алгоритмів, досліджено їх ефективність для розв'язування задачі глобальної оптимізації числових функцій. В результаті обчислювальних експериментів встановлено, що в окремих випадках алгоритм зозулі $\epsilon$ більш ефективним у порівнянні з іншими. При цьому кожен популяційний алгоритм містить ряд варійованих параметрів, від значення яких, може сильно залежить їх ефективність. Тому не можна визначити конкретний алгоритм, який завжди дає найкращі результати для всіх функцій.

Завдяки використанню різних тестових функцій виявлено, що популяційні алгоритми дозволяють знайти глобальний мінімум функції будь-якої складності, не накладаючи додаткових обмежень на неї. Розглянуті алгоритми $є$ досить конкурентоздатними та ефективними для оптимізації складних функцій при розв'язуванні практичних задач.

\section{Список використаної літератури:}

1. Карпенко, А. П. Современные алгоритмы поисковой оптимизации. Алгоритмы, вдохновленные природой : учебное пособие / А. П. Карпенко. - Москва : Издательство МГТУ им. Н. Э. Баумана, 2014. $-448 \mathrm{c}$.

2. Субботін, С. О. Неітеративні, еволюційні та мультиагентні методи синтезу нечіткологічних i нейромережних моделей : монографія / С. О. Субботін, А. О. Олійник, О. О. Олійник ; під заг. ред. С. О. Субботіна. - Запоріжжя : ЗНТУ, 2009. - 375 с.

3. Карпенко, А. П. Популяционные алгоритмы глобальной поисковой оптимизации. Обзор новых и малоизвестных алгоритмов / А. П. Карпенко // Приложение к журналу «Информационные технологии». - 2012. - № 7. - С. 1-32.

4. Yang, X. S. Firefly algorithm, stochastic test functions and design optimization / X. S. Yang // International Journal of Bio-inspired Computation. - 2010.- Vol. 2 (2). - P. 78-84.

5. Yang, X. S. A new metaheuristic bat-inspired algorithm / X. S. Yang // Nature Inspired Cooperative Strategies for Optimization (NICSO 2010). - 2010. - Vol. 284. - P. 65-74.

6. Yang, X. S. Bat algorithm for multi-objective optimization / X. S. Yang // International Journal of BioInspired Computation. - 2011. - Vol. 3. - № 5. - P. 267-274.

7. Красношлык, Н.А. Решение задачи глобальной оптимизации модифицированным алгоритмом летучих мышей / Красношлык Н.А. // Радіоелектроніка. Інформатика. Управління. - 2015. - № 4(35). - C. 96-103.

8. Yang, X. S. Cuckoo search via Lévy flights / X. S. Yang, S. Deb // World Congress on Nature \& Biologically Inspired Computing (NaBIC 2009) IEEE Publications. - 2009. - P. 210-214.

\section{References:}

1. Karpenko, A. P. (2014). Modern search engine optimization algorithms. Nature-Inspired Algorithms: A Tutorial / A. P. Karpenko. - Moskva : Izdatelstvo MGTU im. N. E. Baumana [in Russian].

2. Subbotin, S. O., Oliinyk, A. O., Oliinyk, O. O. (2009). Non-iterative, evolutionary and multiagent methods of synthesis of fuzzy and neural network models. - Zaporizhzhia : ZNTU [in Ukrainian].

3. Karpenko, A. P. (2012). Population algorithms for global search engine optimization. Review of new and little-known algorithms. Prilozheniye k zhurnalu «Informatsionnyye tekhnologii», 7, 1-32 [in Russian].

4. Yang, X. S. (2010). Firefly algorithm, stochastic test functions and design optimization. International Journal of Bio-inspired Computation, Vol. 2 (2), 78-84.

5. Yang, X. S. (2011). A new metaheuristic bat-inspired algorithm. Nature Inspired Cooperative Strategies for Optimization (NICSO 2010), Vol. 284, 65-74.

6. Yang, X. S. (2011). Bat algorithm for multi-objective optimization. // International Journal of Bio-Inspired Computation, Vol. 3(5), 267-274. 
7. Krasnoshlyk, N.A. (2015). Solution of the global optimization problem by the modified bat algorithm. Radioelektronika. Informatyka. Upravlinnia, № 4(35), 96-103 [in Ukrainian].

8. Yang, X. S., Deb, S. (2009). Cuckoo search via Lévy flights. World Congress on Nature \& Biologically Inspired Computing (NaBIC 2009) IEEE Publications, 210-214.

\section{PSHENISHNIY Oleksandr,}

Student, The Bohdan Khmelnytsky National University of Cherkasy, Ukraine

KRASNOSHLYK Nataliia,

$\mathrm{PhD}$, Senior Lecturer, The Bohdan Khmelnytsky National University of Cherkasy, Ukraine

\section{INVESTIGATION OF THE EFFICIENCY OF POPULATION ALGORITHMS FOR SOLVING GLOBAL OPTIMIZATION PROBLEMS}

Introduction. The solution of many technical, economic, physical, biomedical and other problems comes down to global optimization. Meta-heuristic methods are widely used, which involve the simultaneous processing of several possible solutions to the optimization problem. Relevant methods in the literature are called population, multi-agent and swarm intelligence algorithms.

Purpose. The purpose of this article is to implement and investigation the effectiveness of population methods bat algorithm, firefly algorithm and cuckoo search to solve global optimization problems.

Results. Population algorithms bat algorithm, firefly algorithm and cuckoo search are implemented in MATLAB R2012b environment.

These algorithms contain a number of varied parameters, the value of which may greatly affect their effectiveness. In addition, the influence of these parameters strongly depends on the type of objective function. Therefore, the optimal values of the input parameters for the considered algorithms must be selected in each case individually.

The results of computational experiments have shown that in some cases the cuckoo algorithm is more efficient than other algorithms for solving the global optimization problem.

In general, the considered population algorithms are an effective alternative to the classical methods of solving optimization problems, as they are simple for software implementation, unpretentious to the type of objective function and allow to find a solution with relatively high accuracy.

Conclusion. The software implementation of bat algorithm, firefly algorithm and cuckoo search is performed and their efficiency for solving the problem of global optimization of numerical functions is investigated. Each population algorithm contains a number of varied parameters, the value of which may greatly affect their effectiveness. Therefore, it is not possible to determine a specific algorithm that always gives the best results for all functions.

Due to the use of various test functions, it was found that population algorithms allow to find the global minimum of a function of any complexity, without imposing additional restrictions on it. The considered algorithms are quite competitive and effective for optimization of complex functions in solving practical problems.

Keywords: population algorithm, swarm intelligence, global optimization, bat algorithm, firefly algorithm, cuckoo search. 